S. Cora Verduyn

Ruud Zaremba

Jolanda van der Velden

Ger J. M. Stienen

\title{
Effects of contractile protein phosphorylation on force development in permeabilized rat cardiac myocytes
}

Received: 20 February 2007

Returned for 1. revision: 7 March 2007

1. Revision received: 28 March 2007

Returned for 2. revision: 18 April 2007

2. Revision received: 30 April 2007

Accepted: 30 April 2007

Published online: 5 June 2007
S. C. Verduyn $\cdot$ R. Zaremba

J. van der Velden · Prof. Dr. G. J. M. Stienen (凶)

Laboratory for Physiology

Faculty of Medicine

Institute for Cardiovascular Research

(ICaR-VU)

VU University Medical Center (VUMC)

Van der Boechorststraat 7

1081 BT Amsterdam, The Netherlands

Tel.: +31-20/4448-110

Fax: +31-20/4448-255

E-Mail: g.stienen@vumc.nl
Abstract The phosphorylation status of myofibrillar proteins influences the $\mathrm{Ca}^{2+}$ responsiveness of the myofilaments, but the contribution of and the interaction between the individual components is poorly characterized. Therefore, in Langendorff perfused rat hearts $(n=30)$, the phosphorylation levels of cardiac myosin binding protein-C (cMyBP-C), troponin I and $\mathrm{T}$ (cTnI, cTnT) and myosin light chain 1 and 2 (MLC-1, MLC-2) were determined by 1- and 2-dimensional gel electrophoresis. Isometric force development, its $\mathrm{Ca}^{2+}$-sensitivity, the rate of tension redevelopment $\left(\mathrm{k}_{\mathrm{tr}}\right)$ and passive force $\left(\mathrm{F}_{\text {pas }}\right)$ were studied at optimal sarcomere length $(2.2 \mu \mathrm{m})$ in mechanically isolated, permeabilized cardiomyocytes at $15^{\circ} \mathrm{C}$. Protein phosphorylation was varied by: 1) blocking spontaneous cardiac activity by lidocaine (0.35 mM; Quiescence); 2) electrical stimulation of the hearts at $5 \mathrm{~Hz}$ (Contraction) and 3. treatment of contracting hearts with Isoprenaline $(1 \mu \mathrm{M})$. MLC-2 phosphorylation was increased in the Contraction group almost 2-fold, relative to the Quiescence group, whereas cMyBP-C and cTnI phosphorylation remained the same. Isoprenaline resulted in 3.7-fold increases in both cMyBP-C and cTnI phosphorylation, but did not result in a further increase in MLC-2 phosphorylation. No significant differences were found in maximum force and $\mathrm{k}_{\mathrm{tr}}$ between groups, both before and after protein kinase $\mathrm{A}$ (PKA) treatment. $\mathrm{Ca}^{2+}$-sensitivity in the Contraction and Isoprenaline groups was significantly reduced in comparison to the Quiescence group. These differences were largely abolished by PKA and $\mathrm{F}_{\text {pas }}$ was reduced. These results highlight the impact of PKA-dependent phosphorylation on $\mathrm{Ca}^{2+}$-sensitivity and provide evidence for an interaction between the effects of TnI and MLC-2 phosphorylation.

Key words contractile function $-\mathrm{Ca}^{2+}$-sensitivity - cardiac - myocyte phosphorylation

\section{Introduction}

The activity of the contractile apparatus in cardiac myocytes is determined by the intracellular $\mathrm{Ca}^{2+}$ concentration and the sensitivity of the myofilaments to $\mathrm{Ca}^{2+}$. The $\mathrm{Ca}^{2+}$-sensitivity of the myofilaments is modulated by the delicate balance between phosphorylation by kinases, e.g. protein kinase A and C (PKA and PKC), myosin light chain kinase (MLCK) and the $\mathrm{Ca}^{2+}$ calmodulin dependent kinase II (CaMK II), and dephosphorylation by phosphatases, e.g. protein phosphatase 1 and $2 \mathrm{~A}$ (PP-1 and PP-2A). For recent overviews see $[2,8,22]$. In the last decades, the impact of phosphorylation on $\mathrm{Ca}^{2+}$-sensitivity of only a limited number of contractile proteins has been resolved, whereas the interactions between the various proteins are largely unclear.

One of the proteins whose role is not completely un- 
derstood is myosin binding protein $\mathrm{C}$ (CMyBP-C). This approximately $150 \mathrm{kDa}$ protein, discovered more than 30 years ago, is part of the thick (myosin) filament [30] and shows up as the third $(=\mathrm{C})$ band in an SDS gel from crude myosin [35]. The interest in the functional role of $\mathrm{cMyBP}-\mathrm{C}$ has risen with the discovery of frequently occurring mutations in the $M Y B P C 3$ gene that result in the phenotype of hypertrophic cardiomyopathy [e.g. 29]. It has been found that the $\mathrm{C}$ terminal part of cMyBP-C binds to titin and to the light meromyosin region of myosin $[9,21]$, while the $\mathrm{N}$ terminus binds to the myosin $\mathrm{S} 2$ region $[13,20]$. The $\mathrm{N}$ terminal region of rat cardiac cMyBP-C contains three serine phosphorylation sites (S279, S288, S308), phosphorylatable with different stoichiometry by PKA and PKC [26]. Recently, results have been presented indicating the existence of additional phosphorylation sites [45]. Several lines of evidence suggest that phosphorylation of S288 by CaMK II is required before S279 and S308 can be phosphorylated by PKA $[12,24,33]$. On the other hand, cMyBP-C can be dephosphorylated in vitro both by PP-1 and PP-2A [34]. As a consequence of the presence of these multiple phosphorylation sites and the complex signal transduction routes involved, the functional effects of $\mathrm{cMyBP}-\mathrm{C}$ phosphorylation are largely unclear.

It has been proposed that $\mathrm{CMyBP}-\mathrm{C}$ phosphorylation modulates the interaction between cMyBP-C and the S2 region of myosin $[13,20]$ resulting in an increase in the proximity of myosin to actin. This would enhance the probability of crossbridge formation [15, 37, 43]. Accordingly, the PKA-mediated phosphorylation of cMyBP-C might contribute to the increased cardiac output in response to $\beta$-adrenergic stimulation [37].

The phosphorylation of myosin light chain 2 (MLC2), cardiac troponin $\mathrm{T}(\mathrm{c} \operatorname{Tn} \mathrm{T})$ and troponin $\mathrm{I}(\mathrm{cTnI})$ has considerable impact on contractile function as such, but could also modulate the effects of cMyBP-C phosphorylation and vice versa. For instance, recently it has been suggested from a study using cMyBP-C knockout mice that myofilament desensitisation induced by PKA requires the presence of cMyBP-C [4]. MLC-2 phosphorylation by the $\mathrm{Ca}^{2+}$-calmodulin-dependent MLCK results in an increase in $\mathrm{Ca}^{2+}$-sensitivity [39]. In human tissue, our laboratory has presented evidence that the effects of MLC-2 dephosphorylation depend on the level of cTnI phosphorylation, i.e. an interaction between the effect of the phosphorylation of a thin (actin) filament protein and that of a thick (myosin) filament protein [42].

Therefore, in the present study we induced differences in the degree of phosphorylation of the myofilaments to explore the role of phosphorylation of cMyBP$\mathrm{C}$ in isolated rat ventricular myocytes under physiological conditions, taken into account the phosphorylation levels of the other contractile proteins such as MLC-2, cTnT and cTnI.

\section{Methods}

A thoracotomy was performed on Wistar rats $(300 \pm 7 \mathrm{~g})$ anaesthetised with ketamine $0.2 \mathrm{ml} / \mathrm{kg}$ i. $\mathrm{m}$. and pentobarbital $60 \mathrm{mg} / \mathrm{kg}$ i.p. The heart was quickly excised and placed in ice cold Tyrode solution (in $\mathrm{mM}: \mathrm{NaCl}: 120$, $\mathrm{KCl}: 5, \mathrm{MgCl}_{2}: 1.2, \mathrm{NaH}_{2} \mathrm{PO}_{4}: 2, \mathrm{NaHCO}_{3}: 27$, d-glucose: 10 saturated with $95 \% \mathrm{O}_{2}$ and $5 \% \mathrm{CO}_{2}$ ) supplemented with $30 \mathrm{mM}$ 2,3-butanedione monoxime (BDM). The "Principles of laboratory animal care" (NIH publication No 86-23, revised 1985) were followed and all protocols were approved by the Animal Experimental Welfare Committee of the VU University Medical Center. The $\mathrm{CaCl}_{2}$ concentrations in the Tyrode solution were either $0.2 \mathrm{mM}, 1.36 \mathrm{mM}$ or $2.5 \mathrm{mM}$, as specified in each subprotocol. The aorta was cannulated and the complete heart was mounted on a Langendorff apparatus in which coronary perfusion was maintained at $15 \mathrm{ml} / \mathrm{min}$ using $95 \% \mathrm{O}_{2}-5 \% \mathrm{CO}_{2}$ equilibrated Tyrode solution without $\mathrm{BDM}$ at $37^{\circ} \mathrm{C}(\mathrm{pH}$ 7.4). The atria were removed and the ventricles could be stimulated electrically via two platinum electrodes.

We aimed at different $\mathrm{cMyBP}-\mathrm{C}$ phosphorylation levels and used different experimental conditions as tools to achieve this. Phosphorylation of $\mathrm{cMyBP}-\mathrm{C}$ will be low in quiescent hearts perfused with lidocaine at a relatively low $\mathrm{Ca}^{2+}$ concentration [32]. In theory, higher levels of phosphorylation can be obtained by $\beta$-adrenergic stimulation, enhancement of the CaMK II activity by an increase in the time averaged intracellular $\mathrm{Ca}^{2+}$ concentration, and/or by blockade of phosphatase activity [11, 28]. These considerations led to the following experimental groups. Hearts $(n=30)$ were perfused according to Langendorff for $90 \mathrm{~min}$ at $37^{\circ} \mathrm{C}$ with Q1: $0.2 \mathrm{mM} \mathrm{Ca}^{2+}$ and $0.35 \mathrm{mM}$ lidocaine (Lido) to attain quiescence $(\mathrm{n}=4), \mathrm{Q} 2$ : physiological $\mathrm{Ca}^{2+}(1.36 \mathrm{mM})+$ Lido $(\mathrm{n}=5)$, $\mathrm{C} 1: 1.36 \mathrm{mM} \mathrm{Ca}^{2+}$, stimulation at $5 \mathrm{~Hz}(\mathrm{n}=8), \mathrm{C} 2: 5 \mathrm{~Hz}$ stimulation at a high $\mathrm{Ca}^{2+}(2.5 \mathrm{mM})+$ okadaic acid (OA: $0.1 \mu \mathrm{M})(\mathrm{n}=5)$, Iso1: $1.36 \mathrm{mM} \mathrm{Ca}^{2+}, 5 \mathrm{~Hz}$ stimulation followed by $2 \mathrm{~min}$ of Isoprenaline $(1 \mu \mathrm{M})(\mathrm{n}=4)$ and Iso2: $1.36 \mathrm{mM} \mathrm{Ca}^{2+}, 5 \mathrm{~Hz}$ stimulation + OA followed by $2 \mathrm{~min}$ of Isoprenaline + OA $(n=4)$.

Immediately after interruption of the Langendorff perfusion the heart was flash frozen in liquid nitrogen. The left ventricle (LV) plus septum were separated from the rest of the heart and stored at $-80{ }^{\circ} \mathrm{C}$ until further analysis.

\section{Myocyte measurements}

A small piece $(\sim 25 \mathrm{mg})$ of $\mathrm{LV}$ tissue was defrosted in cold relaxing solution, containing in $\mathrm{mM}$ free $\mathrm{Mg}^{2+}: 1, \mathrm{KCl}$ : 100, EGTA: 2, Mg-ATP: 4, imidazole: 10 (pH 7.0, adjusted with $\mathrm{KOH}$ ). This piece was cut into small pieces with scissors and homogenized in 5-10 s, using a tissue ho- 
mogenizer. The resultant suspension of small clumps of myocytes, single myocyte-sized preparations and cell fragments was treated with $0.3 \%$ Triton X-100 in relaxing solution $(5 \mathrm{~min})$, in order to permeabilize the cardiomyocytes. The suspension was washed two times in relaxing solution without Triton and kept at $0{ }^{\circ} \mathrm{C}$ for $6-8$ $\mathrm{h}[41]$.

A single myocyte was attached with silicon adhesive to thin stainless steel needles while viewed by an inverted microscope. One needle was attached to a force transducer (SensoNor, Horten, Norway) and the other to a piezoelectric motor (Physike Instrumente, Waldbrunn, Germany), both connected to joystick-controlled micromanipulators. During cell attachment and subsequent force measurements myocytes were viewed at $320 \mathrm{X}$ magnification. Images were captured by means of a CCD camera and stored on a personal computer. See Fig. 1 for a typical example. Average sarcomere length was determined by means of a spatial Fourier transform as described previously and adjusted to approximately $2.2 \mu \mathrm{m}[6]$. The diameters of the preparation were measured microscopically, in two almost perpendicular directions. Cross-sectional area was calculated assuming an elliptical cross-section.

After curing of the glue for $50 \mathrm{~min}$, the preparation was transferred from the mounting area to a small temperature controlled well $\left(15^{\circ} \mathrm{C}\right.$; volume $\left.79 \mu \mathrm{l}\right)$, containing relaxing solution, from which the myocyte could be transferred to a similar temperature controlled well containing activating solution. Relaxing and activating solutions for force measurements contained, respectively (in $\mathrm{mM}$ ): $\mathrm{MgCl}_{2}: 6.48$ and 6.28, $\mathrm{Na}_{2} \mathrm{ATP}: 5.89$ and 5.97, EGTA: 7.0 and 0, CaEGTA: 0 and 7.0. In addition, both contained $14.5 \mathrm{mM}$ phosphocreatine and $60 \mathrm{mM}$ BES ( $\mathrm{pH}: 7.1$, adjusted with $\mathrm{KOH}$ ). The ionic strength of the solutions was adjusted to $180 \mathrm{mM}$ with $\mathrm{K}$-propionate. The $\mathrm{pCa}$, i. e. $-\log _{10}\left[\mathrm{Ca}^{2+}\right]$, of the relaxing and activating solution was, respectively, 9 and 4.5. Calculated free $\mathrm{Mg}^{2+}$ and MgATP concentrations were 1 and $5 \mathrm{mM}$, respectively. Solutions with lower free $\mathrm{Ca}^{2+}$ concentrations

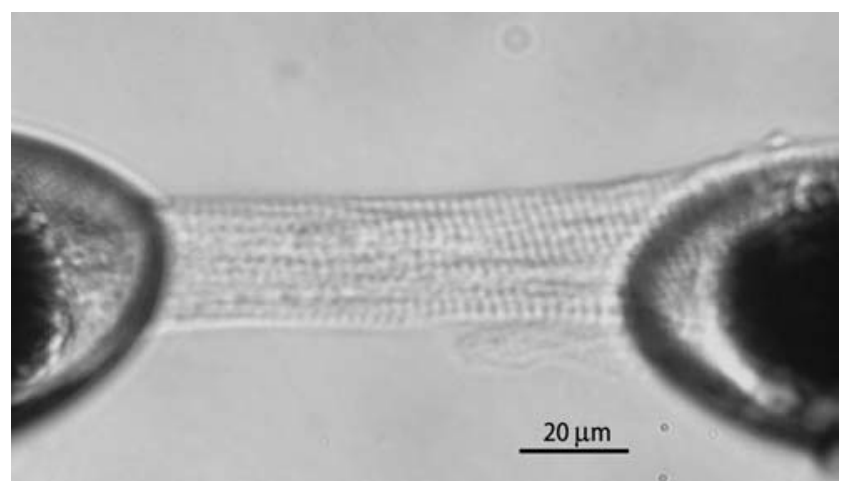

Fig. 1 Single cardiomyocyte, isolated from left ventricular tissue from the Quiescence group, glued between force transducer and piezoelectric motor were obtained by appropriate mixing of the activating and relaxing solutions, assuming an apparent stability constant of the Ca-EGTA complex of $10^{6.56}$.

Isometric force was measured after the preparation was transferred from relaxing to activating solution, by moving the stage of the inverted microscope. When steady force was reached, the myocyte was reduced in length by $20 \%$ within $2 \mathrm{~ms}$ using the piezoelectric motor and restretched after $30 \mathrm{~ms}$ (slack test). As a result of this intervention, force first dropped to zero and then quickly redeveloped to the original steady-state level. A single exponential was fitted to force redevelopment to estimate the rate constant of force redevelopment $\left(k_{t r}\right)$. Subsequently, the myocyte was returned to the relaxing solution, and a second slack test ( $10 \mathrm{~s}$ duration) was performed allowing the determination of passive force $\left(\mathrm{F}_{\mathrm{pas}}\right)$. Active isometric force was calculated from the force level in activating solution $-\mathrm{F}_{\mathrm{pas}}$. Force and length signals were monitored using a pen-recorder and stored on a personal computer. Sampling rate during the experiment was $20 \mathrm{~Hz}$, and 500 or $1000 \mathrm{~Hz}$ during the first slack-test.

$\mathrm{Ca}^{2+}$-sensitivity $\left(\mathrm{pCa}_{50}\right)$ was determined using different $\mathrm{pCa}$ values $(5.0,5.2,5.4,5.6,5.8$ and 6.0) in a random order, bracketed by control activations at $\mathrm{pCa} 4.5$. The initial control force at $\mathrm{pCa} 4.5$ was used to calculate the maximal force per cross-sectional area. The force values at submaximal $\left[\mathrm{Ca}^{2+}\right]$ were normalized to the interpolated control values. Thereafter, the myocytes were incubated for $40 \mathrm{~min}$ at $20^{\circ} \mathrm{C}$ in relaxing solution containing $6 \mathrm{mM}$ dithiothreitol (DTT) (time control) or $6 \mathrm{mM}$ DTT and $100 \mathrm{U} / \mathrm{ml}$ of the catalytic subunit of PKA (Sigma, P2645 from bovine heart) and the $\mathrm{Ca}^{2+}$-sensitivity measurements were repeated. Experimental series where maximum force value during the control activations at pCa 4.5 declined more than $20 \%$, were not used for analysis.

\section{Time dependent phosphorylation in vitro}

Homogenized tissue samples (400 $\mu \mathrm{g}$ dry weight) were incubated in $0.1 \mathrm{ml}$ of relaxing solution with PKA (Calbiochem, Cat. No. 539481, $1250 \mathrm{U} / \mathrm{ml}$ ), protease inhibitor cocktail $10 \mu \mathrm{l} / \mathrm{ml}$ (Sigma, P8340), phosphatase inhibitor cocktail 1 and $2(10 \mu \mathrm{l} / \mathrm{ml}$ each, Sigma, P2850 and P3750, respectively) and $2.5 \mu \mathrm{l} / \mathrm{ml} 10 \%$ Triton for $0,5,10,15,20$, 30 and $60 \mathrm{~min}$ at $30^{\circ} \mathrm{C}$. The reaction was stopped by addition of cold $\left(-20^{\circ} \mathrm{C}\right)$ trichloroacetic acid dissolved in acetone (TCA; $10 \% \mathrm{v} / \mathrm{v})$. Phosphorylation was determined from ProQ diamond stained 1D gradient gels (see below). 


\section{Two-dimensional gel electrophoresis}

Part of the LV was treated with TCA to maintain the phosphorylation status of the contractile proteins. Freeze dried samples were homogenized in 1D sample buffer (62.5 mM TRIS (pH 6.8), 15\% glycerol, 1\% SDS and $1.5 \%$ hydroxyethyldisulfide), and diluted [1:17] in 2D sample buffer (7 M urea, $2.5 \mathrm{M}$ thiourea, $4 \%$ CHAPS, $0.5 \%$ ampholytes $\mathrm{pH} 4-7,10 \%$ glycerol and $10 \%$ isopropanol).2D-gel electrophoresis of the samples $(200 \mu \mathrm{g}$ dry weight) was performed using immobiline strips with a $\mathrm{pH}$ gradient of $4-7$ as described previously [42] to determine MLC-1, MLC-2 and cTnT phosphorylation from the Coomassie stained gels.

\section{ProQ diamond staining}

TCA-treated tissue was washed 3 times in acetone and dissolved in 1D sample buffer with $100 \mathrm{mM}$ DTT, heated $\left(5 \mathrm{~min}\right.$ at $\left.80^{\circ} \mathrm{C}\right)$, centrifuged $\left(20 \mathrm{~min}, 12000 \mathrm{~g}\right.$ at $\left.20^{\circ} \mathrm{C}\right)$ and a sample $(\sim 35 \mu \mathrm{g}$ dry weight in $25 \mu \mathrm{l})$ was applied on a $4-15 \%$ gradient gel (Criterion, BioRad). The gel was run at $100 \mathrm{~V}$ for $30 \mathrm{~min}$ followed by $200 \mathrm{~V}$ for $50 \mathrm{~min}$. The gel was stained for one hour with ProQ Diamond (Molecular Probes, Eugene OR, USA) according to the manufacturer's instructions. Staining was analysed with a LAS-3000 system (Fuji Science Imaging Systems) and AIDA Image analyser software (Isotopenmeßgeräte $\mathrm{GmbH}$, Staubenhardt, Germany). Subsequently, the gel was washed and stained with Sypro Ruby (Molecular Probes) according to the manufacturer's instructions, and analysed.

\section{Data analysis}

The force-pCa relation was fitted using a modified Hill equation

$$
\mathrm{F}\left(\mathrm{Ca}^{2+}\right) / \mathrm{F}_{\max }=\left[\mathrm{Ca}^{2+}\right]^{\mathrm{nH}} /\left(\mathrm{Ca}_{50}{ }^{\mathrm{nH}}+\left[\mathrm{Ca}^{2+}\right]^{\mathrm{nH}}\right)
$$

where $\mathrm{F}$ is steady state force. $\mathrm{F}_{\max }$ denotes the steady isometric force at saturating $\mathrm{Ca}^{2+}$ concentration, the Hill coefficient $\mathrm{nH}$ is a measure of the steepness of the relationship, and $\mathrm{Ca}_{50}\left(\right.$ or $\left.\mathrm{pCa}_{50}\right)$ represents the mid-point of the relation. Values are given as means \pm S. E. M. of $\mathrm{n}$ experiments. Differences between the groups were tested by means of an ANOVA followed by Bonferroni, differences due to PKA treatment were analysed in the main groups using a paired Student's $t$-test. A P-value of $<0.05$ was considered significant.

\section{Results}

The experimental conditions during Langendorff perfusion were varied in order to attain different levels of contractile protein phosphorylation as described in Methods. As can be seen from the overviews of the results in Tables 1 and 2, there were no significant differences in the averaged data of the Quiescence (Q1, Q2), Contraction $(\mathrm{C} 1, \mathrm{C} 2)$ and Isoprenaline subgroups (Iso, Iso + OA). Therefore, for the ease of presentation in the figures and discussion, the data within each of the three main groups were pooled, but the data of the subgroups are given in Tables 1 and 2 .

\section{Force measurements}

An example of the force recording in a single permeabilized cardiomyocyte is shown in Fig. 2. From each animal 2-4 myocytes were analysed in order to calculate the mean force parameter values per animal. Subsequently, the means of the values of all animals in each (sub)group were calculated to allow a comparison with the contractile protein phosphorylation status of the tissue. The maximal active force per cross-sectional area $\left(\mathrm{F}_{\max }\right)$ was measured at saturating $\mathrm{Ca}^{2+}$-concentration ( $\mathrm{pCa} 4.5$ ) and $2.2 \mu \mathrm{m}$ sarcomere length. No significant differences were found between the groups (Fig. 2B; Table 1). The overall averaged value amounted to $16.5 \pm 1.1 \mathrm{kN} / \mathrm{m}^{2}$. Passive force $\left(\mathrm{F}_{\mathrm{pas}}\right)$ also did not differ between groups. The overall averaged value amounted to $2.7 \pm 0.3 \mathrm{kN} / \mathrm{m}^{2}$, i. e. $15 \pm 2 \%$ of the total $\left(F_{\text {tot }}=F_{\text {max }}+F_{\text {pas }}\right)$ force. The rate of force redevelopment $\left(\mathrm{k}_{\mathrm{tr}}\right)$ at saturating $\mathrm{Ca}^{2+}$-concentration did not differ between groups (Fig. 2C; Table 1).

The relation obtained between active force $\left(\mathrm{F}_{\mathrm{act}}\right)$ and the free $\mathrm{Ca}^{2+}$-concentration is shown in Fig. 3. For each cardiomyocyte the data were fitted to the modified Hill equation and for each animal the mean parameter values of $\mathrm{F}_{\max }, \mathrm{pCa}_{50}$ and $\mathrm{nH}$ were obtained and group means were calculated (Fig. 3D; Table 1). These data indicate that $\mathrm{Ca}^{2+}$-sensitivity $\left(\mathrm{pCa}_{50}\right)$ in the Quiescence group was significantly higher than in the Contraction and Isoprenaline groups $(\mathrm{P}<0.05)$. The steepness of the $\mathrm{Ca}^{2+}$-sensitivity relations $(\mathrm{nH})$ did not differ between groups (Table 1). The rate of force redevelopment $\left(\mathrm{k}_{\mathrm{tr}}\right)$ decreased significantly when the $\mathrm{pCa}$ in the activating solutions was increased from 4.5 to 5.4 with $19.4 \pm 2.4 \%$. However, its $\mathrm{Ca}^{2+}$-dependence did not differ between groups.

The impact of saturating PKA-sensitive phosphorylation of cMyBP-C, cTnI and (possibly) titin on force development was studied by repeating the $\mathrm{Ca}^{2+}$-sensitivity measurements after incubation of the cardiomyocytes with the active subunit of PKA. The effect of PKA treatment on the $\mathrm{Ca}^{2+}$-sensitivity of $\mathrm{F}_{\text {act }}$ is illustrated in Fig. 3A, B and C for the Quiescence, Contraction and Iso- 


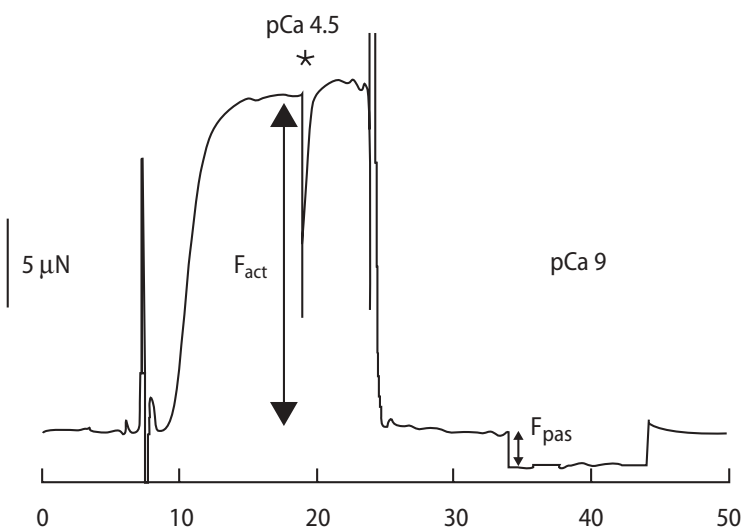

A Time (s)
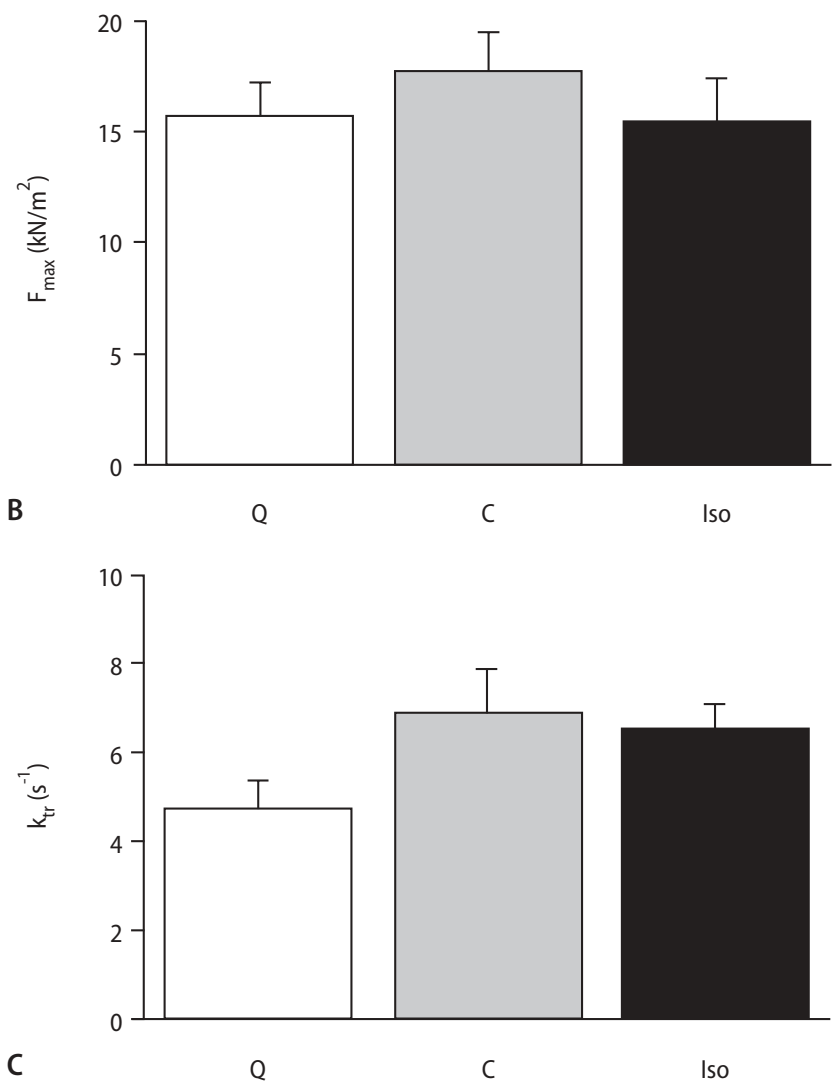

Fig. 2 A Contraction-relaxation sequence recorded from a cardiomyocyte from the Quiescence group at maximally activating $\mathrm{Ca}^{2+}$ concentration (pCa 4.5). * Slack test used to determine the rate of force redevelopment $\left(\mathrm{k}_{\mathrm{tr}}\right)$. $\mathrm{F}_{\mathrm{act}}$ represents the active force development in $\mathrm{Ca}^{2+}$-containing activating solution. $\mathrm{F}_{\text {pas }}$ represents the passive force development measured in relaxing solution ( $\mathrm{pCa}$ 9). $\mathbf{B}$ Averaged values $\left( \pm\right.$ SEM) of the active force development at maximally activating $\mathrm{Ca}^{2+}$-concentration normalized for cross-sectional area $\left(F_{\text {max }}\right)$ in the Quiescence $(Q)$, Contraction $(C)$ and Isoprenaline (Iso) group. C Averaged values ( \pm SEM) of $k_{t r}$ at maximally activating $\mathrm{Ca}^{2+}$ concentration in the Quiescence, Contraction and Isoprenaline group. Both $\mathrm{F}_{\text {max }}$ and $\mathrm{k}_{\mathrm{tr}}$ did not vary significantly between groups (ANOVA)

\begin{tabular}{|c|c|c|c|c|c|c|c|}
\hline 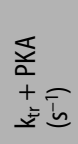 & 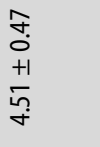 & $\begin{array}{l}+ \\
0 \\
0 \\
+1 \\
8 \\
0 \\
\text { iे }\end{array}$ & 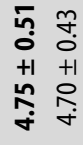 & & 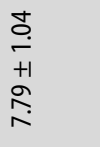 & 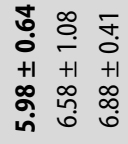 & 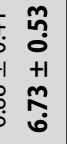 \\
\hline$\overline{ \pm \bar{E}}$ & \begin{tabular}{l} 
ga \\
0 \\
+1 \\
0 \\
0 \\
\multirow{+}{*}{}
\end{tabular} & $\begin{array}{l}\stackrel{+}{\leftarrow} \\
+1 \\
\text { ते } \\
\text { ஸ் }\end{array}$ & 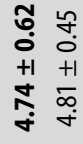 & & $\begin{array}{l}\stackrel{a}{a} \\
+ \\
+1 \\
\frac{1}{\sigma}\end{array}$ & 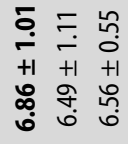 & 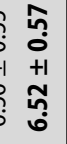 \\
\hline 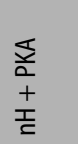 & 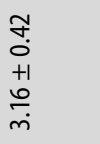 & $\begin{array}{l}\frac{a}{0} \\
0 \\
+1 \\
\stackrel{n}{n} \\
m\end{array}$ & 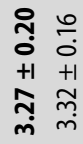 & & $\begin{array}{l}\hat{0} \\
0 \\
+1 \\
\stackrel{\sim}{\sim} \\
\stackrel{+}{0}\end{array}$ & 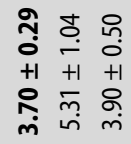 & $\begin{array}{l}8 \\
0 \\
0 \\
1 \\
+1 \\
0 \\
0 \\
\dot{+}\end{array}$ \\
\hline 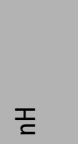 & $\begin{array}{l} \pm \\
\vdots \\
+1 \\
+1 \\
a \\
\dot{m}\end{array}$ & $\begin{array}{l}\text { ָ̊ } \\
0 \\
+1 \\
0 \\
\stackrel{1}{i}\end{array}$ & 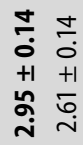 & & $\begin{array}{l}\text { o } \\
0 \\
+1 \\
+1 \\
0 \\
0 \\
+\end{array}$ & 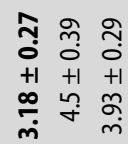 & 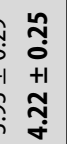 \\
\hline 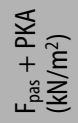 & $\begin{array}{l}\hat{o} \\
+1 \\
\grave{i}\end{array}$ & $\begin{array}{l}+ \\
\vdots \\
+1 \\
m \\
\sim\end{array}$ & $\begin{array}{ll}\breve{y} & m \\
0 & 0 \\
+1 & +1 \\
\tilde{n} & \sim \\
\tilde{N} & \end{array}$ & & $\begin{array}{l}m \\
0 \\
+1 \\
\stackrel{+}{=}\end{array}$ & 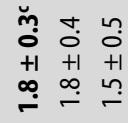 & \begin{tabular}{l}
$m$ \\
0 \\
0 \\
1 \\
+1 \\
0 \\
0 \\
\hdashline
\end{tabular} \\
\hline 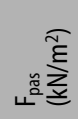 & $\begin{array}{l}\text { ò } \\
\text { +1 } \\
+1 \\
\text { mे }\end{array}$ & $\begin{array}{l}0 \\
0 \\
+1 \\
\stackrel{n}{m}\end{array}$ & $\begin{array}{ll}n & \hat{0} \\
0 & 0 \\
+1 & +1 \\
\hat{n} & m \\
\dot{m} & m\end{array}$ & & $\begin{array}{l}m \\
0 \\
+1 \\
0 \\
\stackrel{-}{-}\end{array}$ & 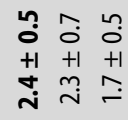 & 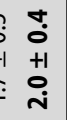 \\
\hline $\begin{array}{l}\frac{5}{a} \\
+ \\
0 \\
\text { J } \\
\alpha\end{array}$ & $\begin{array}{l}0 \\
0 \\
0 \\
+1 \\
5 n \\
\text { in }\end{array}$ & $\begin{array}{l}m \\
0 \\
0 \\
+1 \\
0 \\
0 \\
\dot{0}\end{array}$ & 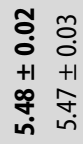 & & $\begin{array}{l}m \\
0 \\
0 \\
+1 \\
\tilde{\sigma} \\
\text { in }\end{array}$ & 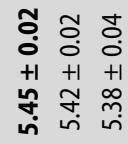 & 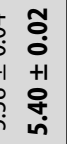 \\
\hline : & $\begin{array}{l}\text { o } \\
0 \\
+1 \\
+1 \\
0 \\
\text { in }\end{array}$ & 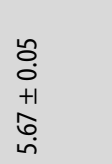 & 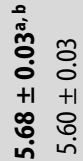 & & 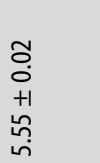 & 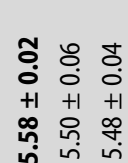 & 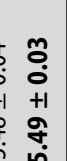 \\
\hline 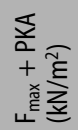 & $\begin{array}{l}\stackrel{n}{\sim} \\
+1 \\
m \\
\tilde{\sigma}\end{array}$ & $\begin{array}{l}\mathscr{0} \\
\dot{m} \\
+1 \\
m \\
m \\
\check{n}\end{array}$ & 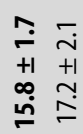 & & $\begin{array}{l}\underset{n}{n} \\
+1 \\
\stackrel{1}{0} \\
\sigma\end{array}$ & 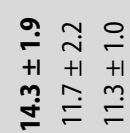 & 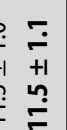 \\
\hline 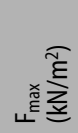 & $\begin{array}{l}\stackrel{0}{i} \\
+1 \\
m \\
0 \\
0\end{array}$ & $\begin{array}{l}\stackrel{+}{+} \\
+1 \\
\stackrel{+}{n}\end{array}$ & 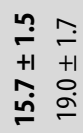 & & $\begin{array}{l}\stackrel{0}{m} \\
+1 \\
+1 \\
m \\
\stackrel{n}{n}\end{array}$ & 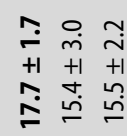 & 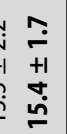 \\
\hline 흥 & 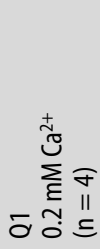 & 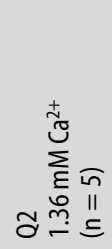 & 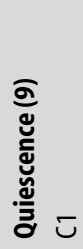 & 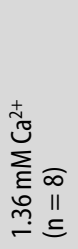 & 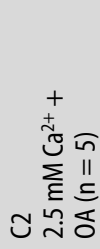 & 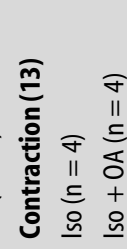 & 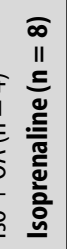 \\
\hline
\end{tabular}


Fig. 3 A, B, C Isometric force normalized to the force at saturating $\mathrm{Ca}^{2+}$ concentration plotted as a function of the $\mathrm{pCa}$ of the activating solution, before and after PKA (100 U/ml) incubation for $40 \mathrm{~min}$ at $20^{\circ} \mathrm{C}$, in the Quiescence, Contraction and Isoprenaline group, respectively. D Bar graph illustrating the differences in $\mathrm{Ca}^{2+}$-sensitivity $\left(\mathrm{pC} \mathrm{a}_{50}\right)$ in the three groups. At baseline $\mathrm{pCa}_{50}$ was significantly lower in the Contraction and Isoprenaline groups than in the Quiescence group ( ${ }^{*} P<0.05$ vs Quiescence group; Bonferroni post hoc test). After PKA treatment $\mathrm{Ca}^{2+}$-sensitivity decreased, and the $\mathrm{pCa}_{50}$ values attained were fairly similar
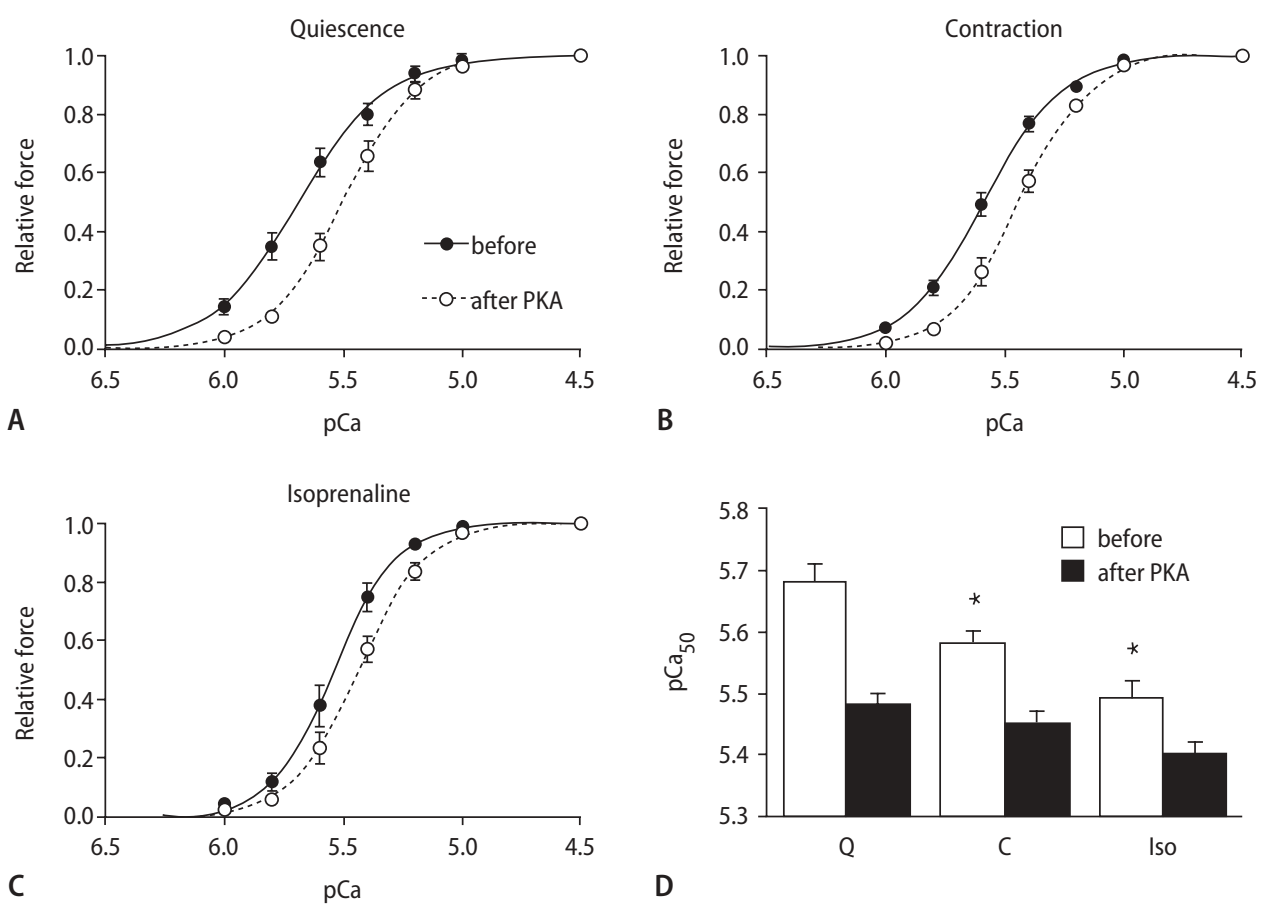

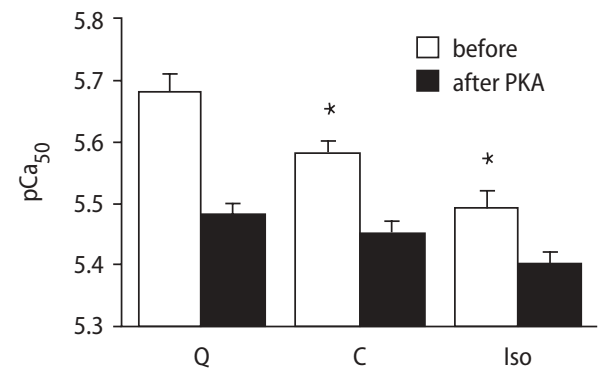

prenaline group, respectively. PKA caused a decrease in $\mathrm{Ca}^{2+}$-sensitivity, which was larger in the Quiescence group than in the Contraction and Isoprenaline group. After PKA, the $\mathrm{pCa}_{50}$ values in the three groups were comparable (Fig. 3D). PKA incubation resulted in a small but significant reduction in $\mathrm{F}_{\mathrm{pas}}$ in the Quiescence and in the Contraction group but did not alter $F_{\max }$ (Table 1). Control incubations without PKA did not have any effect on the force parameters or their $\mathrm{Ca}^{2+}$-sensitivity (data not shown).

To assess the effect of PKA on $\mathrm{k}_{\mathrm{tr}}$, the $\mathrm{k}_{\mathrm{tr}}-\mathrm{pCa}$ and the $\mathrm{k}_{\mathrm{tr}}-\mathrm{F}_{\mathrm{act}}$ relations were studied before and after PKA treatment. Accurate determination of $\mathrm{k}_{\mathrm{tr}}$ was only possible at relatively high forces, i. e. in the $\mathrm{pCa}$ range between 4.5 and 5.4. In general, it appeared that $\mathrm{k}_{\mathrm{tr}}$ at submaximal $\mathrm{pCa}$ values before PKA treatment was somewhat less than the corresponding values before PKA treatment.

\section{Protein analysis}

The endogenous phosphorylation levels of contractile proteins in TCA-treated tissue from the flash frozen hearts were determined from 2D-gels (cTnT, MLC-1 and MLC-2) and from ProQ Diamond stained 1D-gels (cMyBP-C, cTnT, cTnI and MLC-2). Typical examples of the gels obtained are shown in Figs. 4 and 5. The 2D-gels ( $\mathrm{pH}$ range 4-7) allow the distinction between different phosphorylated forms of cTnT, MLC-1 and MLC-2 and permit the quantification of the relative distribution of these forms of each protein. The ProQ Diamond stained
1D-gels are convenient to determine the overall degree of phosphorylation of high molecular weight proteins such as CMyBP-C, and very basic proteins such as cTnI. There was good agreement in the results of protein phosphorylation in the samples of the various groups, where comparisons could be made (cTnT and MLC-2). In both cases $\mathrm{cTnT}$ phosphorylation, expressed as a percentage for 2D-gels or normalized for cMyBP-C protein content in each sample derived from Sypro Ruby stained $1 \mathrm{D}$-gels, did not vary between groups. Therefore normalization of the phosphostaining of other protein bands on the ProQ Diamond gels could be performed relative to the staining intensity of the corresponding cTnT band in each lane.

2D-analysis by means of Sypro Ruby and ProQ Diamond staining and Western Immunoblotting using a monoclonal cTnT antibody (2G3, RDI Research Diagnostics) clearly indicated that the group labeled as cTnT in Fig. 4 consists of a predominant lower molecular weight form, which is mainly mono-phosphorylated and slightly bis-phosphorylated. In addition, a less prominent group with a slightly higher molecular weight at a slightly more acidic $\mathrm{pH}$ can be seen, included in the cTnT box, which possesses a very similar phosphorylation pattern. In addition, the ProQ Diamond stained gel confirmed the identity and distribution of the MLC-2 phospho-species. These images also provided evidence for the presence of a bis-phosphorylated form of MLC-2 with very low abundance. The intensity of this spot was negligible relative to the intensity of the mono-phosphorylated spot. 
Fig. 4 Coomassie blue stained 2D-gel of left ventricular tissue ( $200 \mu \mathrm{g}$ dry weight) of the Quiescence group. On the horizontal axis proteins are separated by isoelectric point ( $\mathrm{pH}$ range: $4-7$ ) and vertically proteins are separated based on molecular weight (top: $200 \mathrm{kDa}$, bottom: $15 \mathrm{kDa}$ ). Abbreviations used: troponin T (cTnT), myosin light chain 1 (MLC-1), myosin light chain 2 (MLC-2). The relative expression of the unphosphorylated (U), mono (P) and bis (2P) phosphorylated forms of a number of proteins can be quantitated from these 2D-gels. The lower panels illustrate the MLC-2 and cTnT regions in 2D-gels from the Quiescence (Q), Contraction (C) and Isoprenaline (Iso) group (approximately $200 \mu \mathrm{g}$ dry weight of sample). MLC-2 was more phosphorylated in the Contraction and Isoprenaline group in comparison to the Quiescence group. The degree of cTnT phosphorylation was very similar as can be seen from the correspondence in the relative distribution of the intensities in the $\mathrm{U}, \mathrm{P}$ and $2 \mathrm{P}$ spots

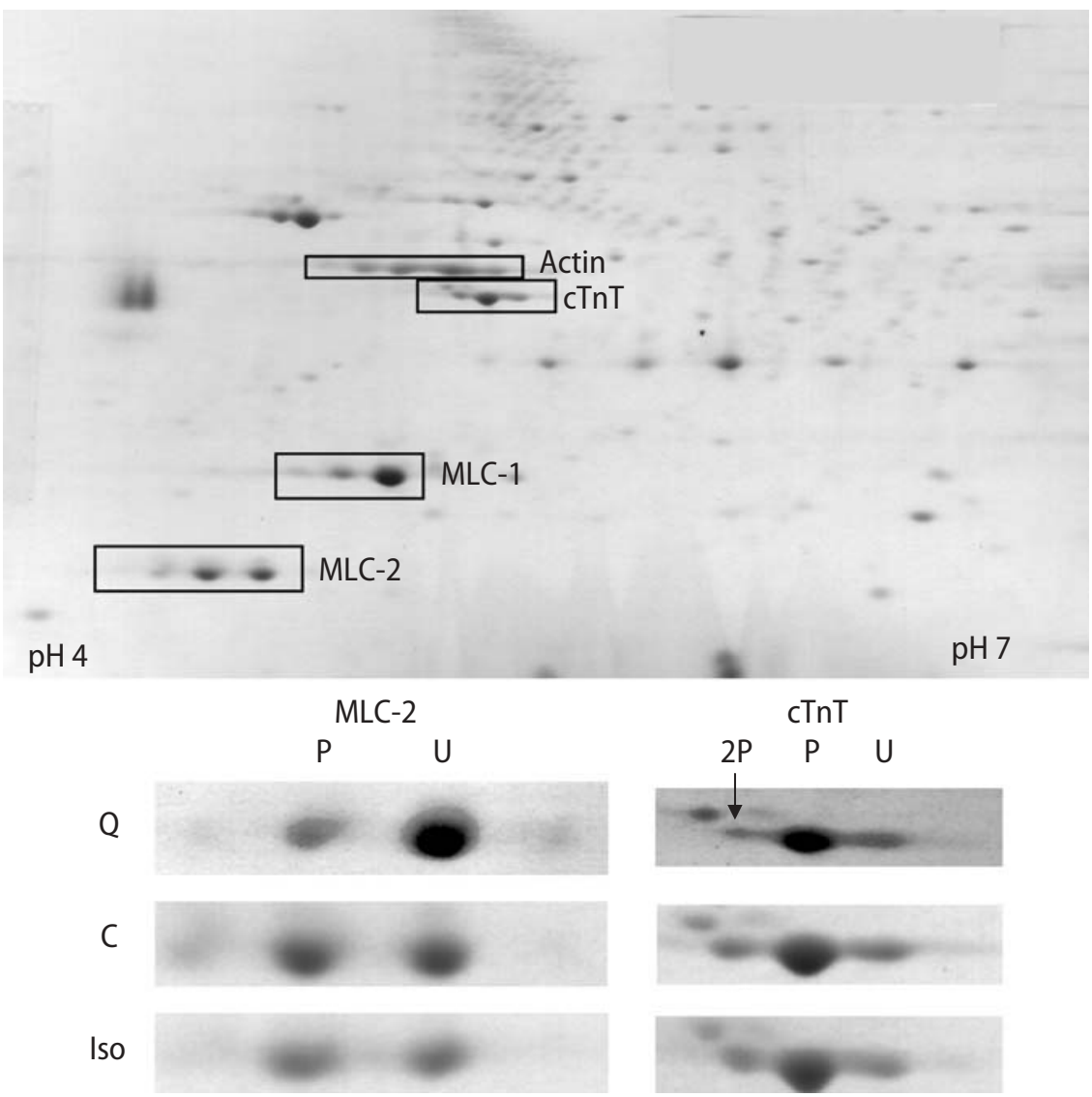

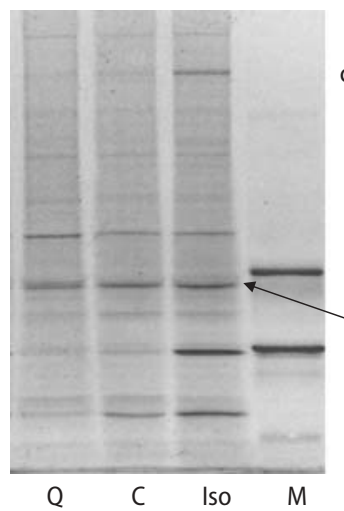

A

Fig. 5 A Representative 4-15\% gradient gel stained with Pro-Q Diamond from samples (approximately $35 \mu \mathrm{g}$ dry weight) of the Quiescence (Q), Contraction (C) and Isoprenaline (Iso) group. B The same gel was subsequently stained with Sypro Ruby to visualize all proteins. $M$ molecular weight PeppermintStick Phosphoprotein marker in which ovalbumin $(45 \mathrm{kDa})$ and $\beta$-casein $(23 \mathrm{kDa})$ are phosphorylated. MHC myosin heavy chain. The degree of phosphorylation of myosin binding protein C (CMyBP-C), troponin I (CTnl) and myosin light chain 2 (MLC-2) was higher in the Isoprenaline group than in the Quiescence and Contraction group, while the phosphorylation status of troponin $\mathrm{T}$ (cTnT) did not vary between groups
From the results presented in Table 2, a comparison can be made with regards to the MLC-2 phosphorylation between the results obtained using ProQ diamond staining of $1 \mathrm{D}$ gels and the Coomassie stained 2D-gels. It can be noted that the correspondence between the results of the two different techniques is good and that the outcome of the statistical analysis of the differences in MLC-2 phosphorylation between experimental groups does not depend on the quantitation method used.

An overview of differences in phosphorylation of cMyBP-C, cTnI and MLC-2 in the Quiescence, Contraction and Isoprenaline group is shown in Fig. 6A, B and $\mathrm{C}$, respectively. A complete summary of the data is given in Table 2. Significant differences were found in the phosphorylation of $\mathrm{CMyBP}-\mathrm{C}, \mathrm{CTnI}, \mathrm{MLC}-1$ and MLC-2 in the three groups (ANOVA), while cTnT phosphorylation (approximately $80 \%$ of total $c \mathrm{TnT}$ ) remained the same. Cardiac MyBP-C and cTnI phosphorylation were markedly increased (3.7-fold) in the Isoprenaline group relative to the Quiescence group $(\mathrm{P}<0.01)$. The average cMyBP-C phosphorylation in the Contraction group was somewhat elevated (1.4-fold) but the difference between the Quiescence and Contraction group was not significant (Bonferroni post-hoc test). MLC-2 phosphorylation increased significantly from $22.4 \%$ in the Quiescence 
Fig. 6 A, B Quantitative analysis of CMyBP-C and cTnl phosphorylation from 1D-gels by Pro- $Q$ Diamond and Sypro Ruby staining. Pro- $Q$ Diamond intensity signals of $\mathrm{CMyBP}-\mathrm{C}$ and $\mathrm{CTnl}$ were normalized to cTnT staining intensity in the same lane. Averaged values ( \pm SEM) values are shown in the Quiescence (Q), Contraction (C) and Isoprenaline (Iso) group. CMyBP-C and CTnl phosphorylation in the Isoprenaline group were significantly increased relative to the Quiescence and Contraction group. C MLC-2 phosphorylation obtained by 2D-gel electrophoresis expressed as percentage of mono-phosphorylated MLC- 2 relative to total MLC- 2 intensity. MLC- 2 phosphorylation in the Contraction and Isoprenaline groups was significantly increased relative to the Quiescence group. D, E Effect of incubation of tissue from the Quiescence group with the active subunit of protein kinase A. CMyBP-C and cTnl phosphorylation increased with the duration of the incubation and saturated after approximately $30 \mathrm{~min}$. The final levels attained are smaller than the corresponding levels reached in the Isoprenaline group, indicating that Isoprenaline phosphorylated other phosphorylation sites in addition to the classical PKA-sites. ${ }^{*} \mathrm{P}<0.05$ vs Quiescence group and $+P<0.05$ vs Contraction group, in a Bonferroni post hoc test

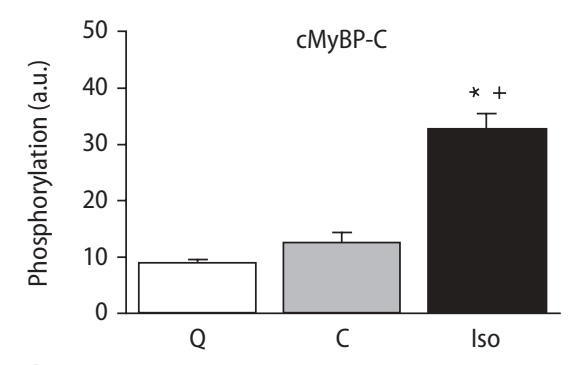

A
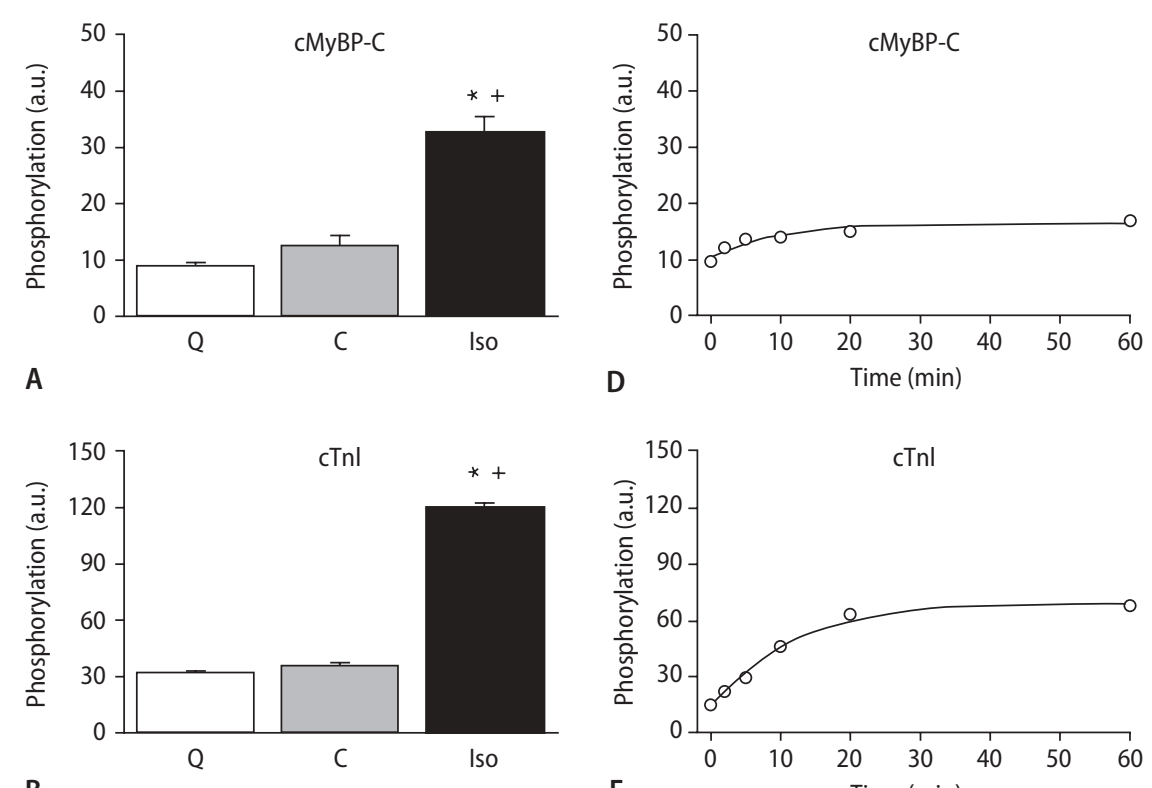

B

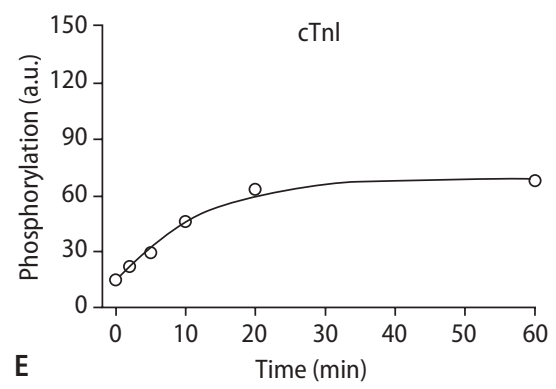

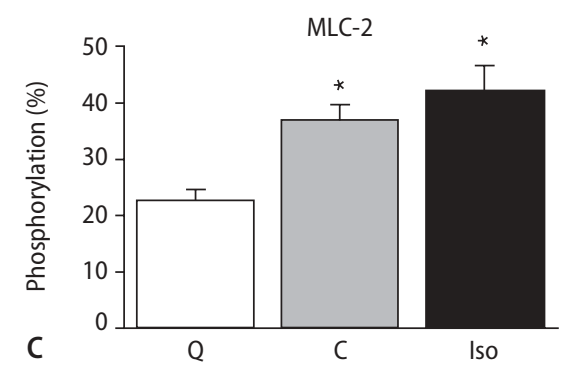

Table 2 Overview of the endogenous phosphorylation levels from 1D- (expressed in arbitrary units) and 2D-gel electrophoresis (expressed as percentage of total protein)

\begin{tabular}{|c|c|c|c|c|c|c|}
\hline Group & cMyBP-C (a. u.) & cTnl (a. u.) & MLC-2 (а. u.) & cTnT (\%) & MLC-1 (\%) & MLC-2 (\%) \\
\hline Q1 $\left(0.2 \mathrm{mM} \mathrm{Ca}^{2+}\right)$ & $7.5 \pm 1.3$ & $31.8 \pm 3.2$ & $22.9 \pm 2.6$ & $81.3 \pm 3.4$ & $13.9 \pm 1.1$ & $23.7 \pm 3.6$ \\
\hline Q2 (1.36 mM Ca $\left.{ }^{2+}\right)$ & $9.8 \pm 0.8$ & $32.3 \pm 4.6$ & $27.1 \pm 4.2$ & $79.6 \pm 2.9$ & $13.2 \pm 0.8$ & $21.3 \pm 2.8$ \\
\hline Quiescence & $8.8 \pm 0.8^{a}$ & $32.1 \pm 2.8^{\mathrm{a}}$ & $25.2 \pm 2.6^{a, b}$ & $80.3 \pm 1.8$ & $13.5 \pm 0.6^{\mathrm{a}}$ & $22.4 \pm 2.1^{a, b}$ \\
\hline $\mathrm{C} 1\left(1.36 \mathrm{mM} \mathrm{Ca}^{2+}\right)$ & $12.9 \pm 2.4$ & $39.8 \pm 4.3$ & $67 \pm 15$ & $81.4 \pm 2.4$ & $13.8 \pm 1.6$ & $35.9 \pm 3.7$ \\
\hline $\mathrm{C} 2\left(2.5 \mathrm{mM} \mathrm{Ca}^{2+}+\mathrm{OA}\right)$ & $12.0 \pm 4.4$ & $30.6 \pm 5.7$ & $60 \pm 11$ & $75.5 \pm 0.9$ & $19.0 \pm 1.7$ & $37.9 \pm 5.2$ \\
\hline Contraction & $12.6 \pm 1.8^{\mathrm{a}}$ & $35.6 \pm 3.0^{\mathrm{a}}$ & $64 \pm 10$ & $79.1 \pm 1.7$ & $15.8 \pm 1.3$ & $36.7 \pm 2.9$ \\
\hline Iso1 & $30.9 \pm 4.6$ & $115 \pm 18$ & $92 \pm 12$ & $75.2 \pm 2.2$ & $17.5 \pm 2.4$ & $41.9 \pm 6.9$ \\
\hline $1502(+0 A)$ & $34.1 \pm 4.3$ & $124 \pm 12$ & $84 \pm 22$ & $77.6 \pm 1.5$ & $20.5 \pm 2.6$ & $42.2 \pm 7.4$ \\
\hline Isoprenaline & $32.5 \pm 3.0$ & $120 \pm 10$ & $88 \pm 12$ & $76.4 \pm 1.3$ & $19.0 \pm 1.7$ & $42.0 \pm 4.7$ \\
\hline
\end{tabular}

${ }^{\text {a }} \mathrm{P}<0.05$ vs Isoprenaline group; ${ }^{\text {b }} \mathrm{P}<0.05$ vs Contraction group

group to $36.7 \%$ in the Contraction group and to $42 \%$ in the Isoprenaline group. MLC-2 phosphorylation did not differ significantly between the Contraction group and Isoprenaline group, indicating that $2 \mathrm{~min}$ of $1 \mu \mathrm{M}$ Isoprenaline did not change MLC-2 phosphorylation. MLC-1 was mainly in the dephosphorylated form; the MLC-1 phosphorylation was increased slightly $(\mathrm{P}<0.05)$ from $13.5 \%$ in the Quiescence group to $19 \%$ in the Isoprenaline group (Table 2). Although the effect of okadaic acid was not significant, this increase might at least partly - be caused by okadaic acid, which blocks PP-1 and PP-2 activity. 


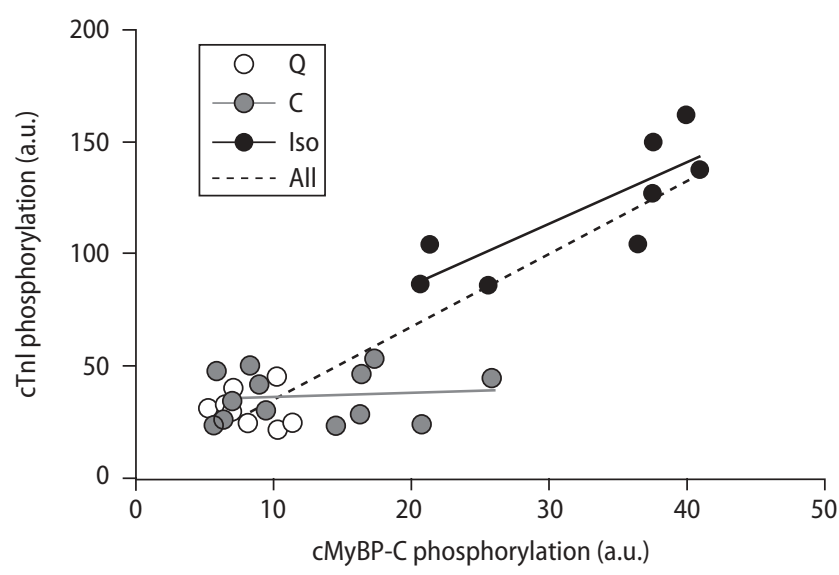

Fig. 7 Relation between $\mathrm{CTnl}$ and CMyBP-C phosphorylation. The overall regression line (interrupted) was calculated on the basis of the individual data points in the Quiescence $(Q$, white), Contraction ( $C$, gray) and Isoprenaline (Iso, black) group $\left(R^{2}=0.78, P<0.0001\right)$. Regression lines are also shown for the Contraction $\left(R^{2}=0.02, P>0.05\right)$ and Isoprenaline group $\left(R^{2}=0.66, P<0.02\right)$

\section{Time-dependent phosphorylation by PKA}

To assess the time course and magnitude of PKA-induced phosphorylation of cMyBP-C and cTnI, suspensions of cardiomyocytes from a sample of the Quiescence group, where phosphorylation was low, were incubated with recombinant PKA as described in the Methods. The data and the single exponential curve fittings are shown in Fig. 6 (panels D and E). In both cases, the time constant amounted to approximately $10 \mathrm{~min}$, indicating that with the activity used, PKA-induced phosphorylation saturated within $60 \mathrm{~min}$. Comparison of the final levels reached with the corresponding levels in Fig. 6A and B clearly illustrates that cMyBP-C and cTnI phosphorylation was not complete in the Contraction group, while Isoprenaline treatment resulted in phosphorylation levels that were higher than those attained after PKA treatment. This latter finding suggests that Isoprenaline also caused phosphorylation of other sites on CMyBP-C and cTnI, distinct from the PKA-sites (cTnI: Ser23/24; cMyBP-C: S279/288/308).

\section{Relation between force development and contractile protein phosphorylation}

As expected from the absence of any difference in $\mathrm{F}_{\max }$, $\mathrm{F}_{\mathrm{pas}}$, and $\mathrm{k}_{\mathrm{tr}}$ between groups, no significant correlations were observed between these parameters and the endogenous levels of cMyBP-C, cTnI and MLC-2 phosphorylation in tissue from the different animals. On the other hand, significant positive correlations were observed between the $\mathrm{pCa}_{50}$ values from the different animals and endogenous phosphorylation levels. $\mathrm{R}^{2}$ values ranged between 0.20 and $0.37(\mathrm{P}<0.02)$, After PKA, the slopes of the regression lines were reduced but the relations remained significant with $\mathrm{R}^{2}$ values of 0.22 and 0.23 , except for MLC-2. $\left(\mathrm{R}^{2}=0.03, \mathrm{P}>0.05\right)$.

The overall correlation between the endogenous cTnI and cMyBP-C phosphorylation levels (Fig. 7) turned out to be positive and highly significant. The relation within the Isoprenaline group was also significant and rather similar to the overall relation. The relations within the Quiescence and Contraction group were not significant. There was some variability in the cMyBP-C phosphorylation levels within the Contraction and Isoprenaline group. This variability, however, did not appear to be associated with the differences in the $\mathrm{Ca}^{2+}$ concentration in the Contraction group nor with the presence of okadaic acid in the Contraction and Isoprenaline subgroups.

\section{Discussion}

The phosphorylation levels of the contractile proteins varied considerably with the experimental conditions used. Pacing the Langendorff perfused hearts at $5 \mathrm{~Hz}$ resulted in an almost 2-fold increase in MLC-2 phosphorylation (relative to the Quiescence group) and, in $\sim 50 \%$ of the cases, in an increase in cMyBP-C phosphorylation, while cTnI phosphorylation remained constant. Addition of $\beta$-agonist Isoprenaline to the electrically paced hearts resulted in 3.7-fold increases, relative to Quiescence, in both cMyBP-C and cTnI phosphorylation. These alterations in phosphorylation had a large impact on $\mathrm{Ca}^{2+}$-sensitivity but not on maximum force and $\mathrm{k}_{\mathrm{tr}}$.

\section{Alterations in contractile protein phosphorylation}

The phosphorylation status of contractile proteins is determined by the kinase-phosphatase balance inside the cardiomyocytes. In quiescent Langendorff-perfused hearts MLC-1, MLC-2, cMyBP-C and cTnI were mainly dephosphorylated, indicating that the relevant balance had been shifted in favour of phosphatase activity. MLC1 phosphorylation increased significantly from $13.5 \pm 0.6 \%$ to $19.0 \pm 1.7 \%$ in the Isoprenaline group. The kinase involved in MLC-1 phosphorylation is unknown: it could be phosphorylated in vitro by MLCK, but only in the presence of ATP $\gamma \mathrm{S}$ and not in the presence of ${ }^{32}$ P-labeled $\gamma$ ATP [27] and, in vivo, by $0.1 \mathrm{mM}$ adenosine [1]. The increase in MLC-2 phosphorylation in the Contraction group with respect of the Quiescence group indicates that a marked increase in intracellular $\mathrm{Ca}^{2+}$ by pacing is required to activate the $\mathrm{Ca}^{2+}$-calmodulin dependent MLCK. The averaged levels of $\mathrm{CMyBP}-\mathrm{C}$ and cTnI phosphorylation in the Contraction group were not significantly increased. However, the variability in cMyBP-C phosphorylation in this group suggests 
that the activity of CaMK II may have been increased near to the threshold for suprabasal cMyBP-C phosphorylation.

The correspondence between the $\mathrm{CMyBP}-\mathrm{C}$ and $\mathrm{cTnI}$ phosphorylation levels in the Quiescence hearts perfused with $0.2 \mathrm{mM}$ and $1.36 \mathrm{mM} \mathrm{CaCl}_{2}$ was unexpected. McClellan et al. [24] reported a large decrease in the level of cMyBP-C phosphorylation when the $\mathrm{Ca}^{2+}$ concentration in the incubation solution for the cardiac trabeculae was reduced from $2.5 \mathrm{mM}$ to $1.25 \mathrm{mM}$. This difference could be explained by a temperature-dependent shift in the kinase-phosphatase balance (e.g. [25]) since our experiments in Langendorff-perfused hearts were carried out at $37^{\circ} \mathrm{C}$, and those of McClellan et al. at 23 ${ }^{\circ} \mathrm{C}$.

Addition of Isoprenaline to the electrically paced (5 $\mathrm{Hz}$ ) heart caused marked elevations of the $\mathrm{CMyBP}-\mathrm{C}$ and cTnI phosphorylation levels, but did not result in a further significant increase in MLC-2 phosphorylation. The increases in $\mathrm{CMyBP}-\mathrm{C}$ and $\mathrm{CTnI}$ phosphorylation are consistent with literature data (e.g. [5]) and can be attributed to the increased activity of PKA but, because of the associated rise in the time-averaged intracellular $\mathrm{Ca}^{2+}$ concentration [2], altered activities of the $\mathrm{Ca}^{2+}$-dependent kinases CaMK II and classical PKC isoforms and, indirectly, of phosphatases such as PP-1 [22] may be involved as well. The notion that Isoprenaline phosphorylates other sites on CTnI and cMyBP-C is supported by the observation that the phosphorylation levels attained exceeded those obtained in the myocyte suspension after PKA treatment. On the other hand, the finding that the phosphorylation level of MLC-2 was not increased may be attributed by substrate specificity of the $\left(\mathrm{Ca}^{2+}-\right.$ dependent) kinases and phosphatases involved.

\section{Phosphorylation and force development}

The maximum force generating capacity $\left(\mathrm{F}_{\max }\right)$ in the different experimental groups studied was very similar. Moreover, as was observed in previous studies (e.g. [16, 40]), $\mathrm{F}_{\max }$ was not influenced by PKA treatment. This indicates that phosphorylation by PKA of cMyBP-C and cTnI did not modulate $\mathrm{F}_{\max }$. These observations are at variance with the results of McClellan et al. obtained in cardiac trabeculae where $\mathrm{CMyBP}-\mathrm{C}$ phosphorylation resulted in an increase of $F_{\max }$. The reason for this difference is unclear and previous data are equivocal: a large body of evidence has accumulated from transgenic animals $[18,38]$ and by adding peptide fragments of cMyBP-C $[14,23]$ as well as extraction of cMyBP-C [15] that $\mathrm{cMyBP}-\mathrm{C}$ is able to modulate the isometric force and kinetics of force generation in cardiac tissue at submaximal levels of activation but not at saturating $\mathrm{Ca}^{2+}$ concentrations. However, other reports indicate that cMyBP-C is able to influence $\mathrm{F}_{\max }[19,20]$.
The $\mathrm{k}_{\mathrm{tr}}$ at saturating $\mathrm{Ca}^{2+}$-concentration and $\mathrm{Ca}^{2+}$-dependence of $k_{t r}$ in the different experimental groups did not differ significantly. The absence of an effect of cMyBP-C phosphorylation on maximum $\mathrm{k}_{\mathrm{tr}}$ is in agreement with the results of Stelzer et al. [36, 38]. Their results at submaximal activation indicate that ablation of murine cardiac cMyBP-C and PKA phosphorylation of cMyBP-C both accelerate the rate of force generation. Our measurements at submaximal activation suggested a small reduction in $\mathrm{k}_{\mathrm{tr}}$ after PKA treatment, i. e. a slowing of force generation, in particular in the Contraction group. It should be noted that we studied the $\mathrm{Ca}^{2+}$-dependence of $\mathrm{k}_{\mathrm{tr}}$ in the pCa range between 4.5 and 5.4, where the $\mathrm{Ca}^{2+}$-dependent reduction in $\mathrm{k}_{\mathrm{tr}}$ was quite modest.

The $\mathrm{Ca}^{2+}$-sensitivity in the Quiescent group was larger than in the Contraction and Isoprenaline groups $(\mathrm{P}<0.05)$. The origin of this difference is not clear, but since the effect of PKA was larger in the Quiescent group than in the Contraction and Isoprenaline groups, we consider it likely that it is a consequence of differences in cAMP-dependent phosphorylation. If this would be the case, minor differences in phosphorylation at low cAMP levels may have a considerably larger impact on $\mathrm{Ca}^{2+}$-sensitivity than at moderate or high levels.

The passive force decreased significantly after PKA treatment. This observation is similar to the findings in our Laboratory in cardiomyocytes isolated from biopsies from heart failure patients with diastolic dysfunction [3]. Recent studies indicate that the reduction in passive force could be caused by the phosphorylation of titin $[10,44]$.

\section{Effects of phosphorylation on $\mathrm{Ca}^{2+}$-sensitivity}

PKA phosphorylation desensitised the myofilaments in all groups. The magnitude of this effect depended on the endogenous phosphorylation levels since similar $\mathrm{pCa}_{50}$ values were attained after PKA treatment. These experiments indicate that the PKA-sensitive phosphorylation sites on $\mathrm{CMyBP}-\mathrm{C}$ and/or $\mathrm{CTnI}$ were not saturated under basal conditions even in the Isoprenaline group. Additional evidence to support this notion originates from the observations that the final phosphorylation levels of cMyBP-C and cTnI in the cardiomyocyte suspension after PKA-treatment exceeded the average values in the Quiescence and Contraction group. The effects of PKA in the Isoprenaline group also indicate that, although the dose used was in the high range of values reported in the literature, Isoprenaline did not result in complete saturation of the PKA sites. Since in preliminary experiments pressure development stabilised within $1 \mathrm{~min}$ following Isoprenaline administration, these observations could be caused by a lag in phosphorylation of contractile proteins relative to that of $\mathrm{Ca}^{2+}$-handling proteins 
and/or a delayed onset of dose-dependent activation of phosphatases.

Since $\mathrm{cMyBP}-\mathrm{C}$ and $\mathrm{cTnI}$ phosphorylation are strongly associated (Fig. 6D), it is not possible from these experiments to distinguish directly between effects of cMyBP-C and cTnI phosphorylation on $\mathrm{Ca}^{2+}$ sensitivity of force development. A number of studies in transgenic animals, however, indicated that cMyBP-C phosphorylation has considerable impact on cardiac contractility, but not directly on $\mathrm{Ca}^{2+}$-sensitivity of isometric force $[7,16,17]$.

Olsson et al. [31] have shown that an increase in MLC2 phosphorylation from 7 to $58 \%$ resulted in an increase in $\mathrm{Ca}^{2+}$-sensitivity corresponding to $0.06 \mathrm{pCa}$ units. Our data provided evidence for an even stronger, inverse association between MLC-2 phosphorylation and $\mathrm{pCa}_{50}$. Regression analysis indicated that this association was lost after PKA treatment. The CMyBP-C and cTnI phosphorylation levels in the Quiescence and Contraction group were very similar. Therefore our results indicate the presence of a strong interaction between the effects of phosphorylation of CTnI and MLC-2 on $\mathrm{Ca}^{2+}$-sensitivity. Since the intrinsic positive effect of MLC-2 phosphorylation did not become visible after PKA treatment, this interaction might be the consequence of the coordinated action of different kinases and phosphatases, resulting in a specific pattern of phosphate incorporation on the interacting proteins.

Acknowledgements This work is part of the research programme of the 'Stichting voor Fundamenteel Onderzoek der Materie (FOM)', which is financially supported by the 'Nederlandse Organisatie voor Wetenschappelijk Onderzoek (NWO)'.

\section{References}

1. Arrell DK, Neverova I, Fraser H, Marban E, Van Eyk JE (2001) Proteomic analysis of pharmacologically preconditioned cardiomyocytes reveals novel phosphorylation of myosin light chain 1 . Circ Res 89:480-487

2. Boknik P, Khorchidi S, Bodor GS, Huke S, Knapp J, Linck B, Lüss H, Muller FU, Schmitz W, Neumann J (2001) Role of protein phosphatases in regulation of cardiac inotropy and relaxation. Am J Physiol 280:H786-H794

3. Borbely A, van der Velden J, Papp Z, Bronzwaer JG, Edes I, Stienen GJM, Paulus WJ (2005) Cardiomyocyte stiffness in diastolic heart failure. Circulation 111:774-781

4. Cazorla O, Szilagyi S, Vignier N, Salazar G, Kramer E, Vassort G, Carrier L, Lacampagne A (2006) Length and protein kinase A modulations of myocytes in cardiac myosin binding protein C-deficient mice. Cardiovasc Res 69:370-380

5. England PJ, Shahid M (1987) Effects of forskolin on contractile responses and protein phosphorylation in the isolated perfused rat heart. Biochem J 246: 687-695

6. Fan D, Wannenburg T, de Tombe PP (1997) Decreased myocyte tension development and calcium responsiveness in rat right ventricular pressure overload. Circulation 95:2312-2317

7. Fentzke RC, Buck SH, Patel JR, Lin $\mathrm{H}$, Wolska BM, Stojanovic MO, Martin AF, Solaro RJ, Moss RL, Leiden JM (1999) Impaired cardiomyocyte relaxation and diastolic function in transgenic mice expressing slow skeletal troponin I in the heart. J Physiol 517:143-157
8. Flashman E, Redwood C, MoolmanSmook J, Watkins H (2004) Cardiac myosin binding protein $\mathrm{C}$ : its role in physiology and disease. Circ Res 94: 1279-1289

9. Freiburg A, Gautel M (1996) A molecular map of the interactions between titin and myosin-binding protein C.Implications for sarcomeric assembly in familial hypertrophic cardiomyopathy. Eur J Biochem 235:317-323

10. Fukuda N, Wu Y, Nair P, Granzier HL (2005) Phosphorylation of Titin Modulates Passive Stiffness of Cardiac Muscle in a Titin Isoform-dependent Manner. J Gen Physiol 125:257-271

11. Garvey JL, Kranias EG, Solaro RJ (1988) Phosphorylation of C-protein, troponin I and phospholamban in isolated rabbit hearts. Biochem J 249:709-714

12. Gautel M, Zuffardi O, Freiburg A, Labeit S (1995) Phosphorylation switches specific for the cardiac isoform of myosin binding protein-C: a modulator of cardiac contraction? EMBO J 14: 1952-1960

13. Gruen M, Prinz H, Gautel M (1999) cAPK-phosphorylation controls the interaction of the regulatory domain of cardiac myosin binding protein $\mathrm{C}$ with myosin-S2 in an on-off fashion. FEBS Lett 453:254-259

14. Herron TJ, Rostkova E, Kunst G, Chaturvedi R, Gautel M, Kentish JC (2006) Activation of Myocardial Contraction by the N-Terminal Domains of Myosin Binding Protein-C. Circ Res 98:1290-1298
15. Hofmann PA, Hartzell HC, Moss RL (1991) Alterations in $\mathrm{Ca}^{2+}$ sensitive tension due to partial extraction of C-protein from rat skinned cardiac myocytes and rabbit skeletal muscle fibers. J Gen Physiol 97:1141-1163

16. Kentish JC, McCloskey DT, Layland J, Palmer S, Leiden JM, Martin AF, Solaro RJ (2001) Phosphorylation of troponin I by protein kinase A accelerates relaxation and crossbridge cycle kinetics in mouse ventricular muscle. Circ Res 88: 1059-1065

17. Konhilas JP, Irving TC, Wolska BM, Jweied EE, Martin AF, Solaro RJ, de Tombe PP (2003) Troponin I in the murine myocardium: influence on length-dependent activation and interfilament spacing. J Physiol 547:951-961

18. Korte FS, McDonald KS, Harris SP, Moss RL (2003) Loaded shortening, power output, and rate of force redevelopment are increased with knockout of cardiac myosin binding protein-C. Circ Res 93: 752-758

19. Kulikovskaya I, McClellan G, Levine R, Winegrad S (2003) Effect of extraction of myosin binding protein $\mathrm{C}$ on contractility of rat heart. Am J Physiol Heart Circ Physiol 285:H857-H865

20. Kunst G, Kress KR, Gruen M, Uttenweiler D, Gautel M, Fink RH (2000) Myosin binding protein $\mathrm{C}$, a phosphorylation-dependent force regulator in muscle that controls the attachment of myosin heads by its interaction with myosin S2. Circ Res 86:51-58

21. Labeit S, Gautel M, Lakey A, Trinick J (1992) Towards a molecular understanding of titin. EMBO J 11:1711-1716 
22. Mattiazzi A, Mundina-Weilenmann C, Guoxiang C, Vittone L, Kranias E (2005) Role of phospholamban phosphorylation on Thr17 in cardiac physiological and pathological conditions. Cardiovasc Res 68:366-375

23. McClellan G, Kulikovskaya I, Flavigny J, Carrier L, Winegrad S (2004) Effect of cardiac myosin-binding protein $\mathrm{C}$ on stability of the thick filament. J Mol Cell Cardiol 37:823-835

24. McClellan G, Kulikovskaya I, Winegrad S (2001) Changes in cardiac contractility related to calcium-mediated changes in phosphorylation of myosinbinding protein $\mathrm{C}$ Biophys J 81: 1083-1092

25. Mitsui T, Kitazawa T, Ikebe M (1994) Correlation between high temperature dependence of smooth muscle myosin light chain phosphatase activity and muscle relaxation rate. J Biol Chem 269:5842-5848

26. Mohamed AS, Dignam JD, Schlender KK (1998) Cardiac myosin-binding protein $\mathrm{C}(\mathrm{MyBP}-\mathrm{C})$ : identification of protein kinase $\mathrm{A}$ and protein kinase $\mathrm{C}$ phosphorylation sites. Arch Biochem Biophys 358:313-319

27. Morano I, Rosch J, Arner A, Ruegg JC (1990) Phosphorylation and thiophosphorylation by myosin light chain kinase: different effects on mechanical properties of chemically skinned ventricular fibers from the pig. J Mol Cell Cardiol 22:805-813

28. Mundina-Weilenmann C, Vittone L, Ortale $\mathrm{M}$, deCingolani $\mathrm{G}$, Mattiazzi A (1996) Immunodetection of phosphorylation sites gives new insights into the mechanisms underlying phospholamban phosphorylation in the intact heart. J Biol Chem 271:33561-33567

29. Richard P, Charron P, Carrier L, Ledeuil C, Cheav T, Pichereau C, Benaiche A, Isnard R, Dubourg O, Burban M, Gueffet JP, Millaire A, Desnos M, Schwartz K, Hainque B, Komajda M; EUROGENE Heart Failure Project (2003) Hypertrophic cardiomyopathy: distribution of disease genes, spectrum of mutations, and implications for a molecular diagnosis strategy. Circulation 107: 2227-2232
30. Offer G, Moos C, Starr R (1973) A new protein of the thick filaments of vertebrate skeletal myofibrils. Extractions, purification and characterization. J Mol Biol 74:653-676

31. Olsson MC, Patel JR, Fitzsimons DP, Walker JW, Moss RL (2004) Basal myosin light chain phosphorylation is a determinant of $\mathrm{Ca}^{2+}$-sensitivity of force and activation dependence of the kinetics of myocardial force development. Am J Physiol 287:H2712-H2718

32. Sarikas A, Carrier L, Schenke C, Doll D, Flavigny J, Lindenberg KS, Eschenhagen T, Zolk O (2005) Impairment of the ubiquitin-proteasome system by truncated cardiac myosin binding protein $\mathrm{C}$ mutants. Cardiovascular Research 66:33-44

33. Schlender KK, Bean LJ (1991) Phosphorylation of chicken cardiac C-protein by calcium/calmodulin-dependent protein kinase II. J Biol Chem 266: 2811-2817

34. Schlender KK, Hegazy MK, Thysseril TJ (1987) Dephosphorylation of cardiac myofibril C-protein by protein phosphatase 1 and protein phosphatase $2 \mathrm{~A}$. Biochim Biophys Acta 928:312-319

35. Starr R, Offer G (1971) Polypeptide chains of intermediate molecular weight in myosin preparations. FEBS Letters 15:40-44

36. Stelzer JE, Fitzsimons DP, Moss RL (2006) Ablation of myosin-binding protein-C accelerates force development in mouse myocardium. Biophys J 90: 4119-4127

37. Stelzer JE, Patel JR, Moss RL (2006) Acceleration of stretch activation in murine myocardium due to phosphorylation of myosin regulatory light chain. J Gen Physiol 128:261-272
38. Stelzer JE, Patel JR, Moss RL (2006) Protein kinase A-mediated acceleration of the stretch activation response in murine skinned myocardium is eliminated by ablation of cMyBP-C. Circ Res 99:884-890

39. Sweeney HL, Bowman BF, Stull JT (1993) Myosin light chain phosphorylation in vertebrate striated muscle: regulation and function. Am J Physiol 264: C1085-C1095

40. van der Velden J, de Jong JW, Owen VJ, Burton PB, Stienen GJM (2000) Effect of protein kinase A on calcium sensitivity of force and its sarcomere length dependence in human cardiomyocytes. Cardiovasc Res 46:487-495

41. van der Velden J, Klein LJ, van der Bijl M, Huybregts MAJM, Stooker W, Witkop J, Eijsman L, Visser CA, Visser FC, Stienen GJM (1998) Force production in mechanically isolated cardiac myocytes from human ventricular muscle tissue. Cardiovasc Res 38: 414-423

42. van der Velden J, Papp Z, Boontje NM, Zaremba R, de Jong JW, Janssen PM, Hasenfuss G, Stienen GJM (2003) The effect of myosin light chain 2 dephosphorylation on $\mathrm{Ca}^{2+}$-sensitivity of force is enhanced in failing human hearts. Cardiovasc Res 57:505-514

43. Weisberg A, Winegrad S (1996) Alteration of myosin cross bridges by phosphorylation of myosin-binding protein $\mathrm{C}$ in cardiac muscle. Proc Natl Acad Sci USA 93:8999-9003

44. Yamasaki R, Wu Y, McNabb M, Greaser M, Labeit S, Granzier H (2002) Protein kinase A phosphorylates titin's cardiacspecific N2B domain and reduces passive tension in rat cardiac myocytes. Circ Res 90:1181-1188

45. Yuan C, Guo Y, Ravi R, Przyklenk K, Shilkofski N, Diez R, Cole RN, Murphy AM (2006) Myosin binding protein C is differentially phosphorylated upon myocardial stunning in canine and rat hearts - evidence for novel phosphorylation sites. Proteomics 6:4176-4186 